\title{
Adipocyte Dynamics in Hypothalamic Obese Mice during Food Deprivation and Refeeding
}

\author{
Masaharu OchI, ${ }^{1}$ Hiroshi Furukawa, ${ }^{1}$ Hiroshi Yoshioka, ${ }^{1}$ \\ Tadashi Sawada, ${ }^{1}$ Tomoichi Kusunoki, ${ }^{1}$ \\ and Takanori HATTORI ${ }^{2}$ \\ ${ }^{1}$ Department of Pediatrics, Kyoto Prefectural University of Medicine, \\ Kamigyo-ku, Kyoto 602, Japan \\ ${ }^{2}$ Department of Pathology, Shiga University of Medical Science, \\ Otsu, Shiga 520-21, Japan
}

(Received October 29, 1990)

\begin{abstract}
Summary Effect of hypothalamic lesions on regulation of body weight and fat cell dynamics in obese mice were examined during refeeding after prolonged food deprivation. Obese mice, which were treated with monosodium glutamate for 5 postnatal days and had ventromedial nuclear lesions in the hypothalamus, were used. When adult obese mice were given a glucose electrolyte solution for 20-40 days, the body weight dropped to about $45 \%$ of their pre-treatment weight. After reinstituted feeding of normal mouse food ad libitum, their body weight and adipose tissue weight returned to pre-starvation level. Tritiated thymidine autoradiography revealed that cell proliferation occurred in the early stages of refeeding and some fat cells were renewed in the epididymal adipose tissue. Fat cell renewal was found more active in the experimental group than in the control. Thereafter, fat cell size increased gradually via fat storage. These obese mice were found to have the capacity to regulate their body weight and adipose tissue not only through fat storage but also by increasing number of fat cells, in order to replace the cells which were lost during starvation. Therefore, ventromedial nuclear lesion in the hypothalamus does not influence the regulatory mechanism of adipose tissue during starvation and refeeding.
\end{abstract}

Key Words monosodium glutamate, epididymal adipose tissue, ${ }^{3} \mathrm{H}$-thymidine autoradiography

When adult animals are refed ad libitum after food deprivation, they regain all previously lost weight, with their body weights returning to pre-deprivation level (1-3). This phenomenon has been explained by the concept that individual animals have their own weight "set point," which regulates body weight physiologically at a specific level (4-6). 
More recently, obesity has been recognized to be not only a regulatory failure of weight, but also the result of the regulation at an elevated set point. Some forms of obesity (genetic and diet induced) seemed to be regarded as examples of regulation at an elevated set point, while other forms (hypothalamic obesity) seem to result from a regulatory dysfunction $(4,5)$.

In the present study, we investigated the following points about obese mice that had ventromedial nuclear lesion of the hypothalamus induced by monosodium glutamate (MSG). 1) Can the MSG-treated (obese) mice, of which body weight dropped during food deprivation, regain weight to its previous levels (high set point level) after refeeding? 2) What morphological changes occur in the fatty tissue of MSG-treated (obese) mice that are deprived of food and subsequently refed? 3) Are there any differences in the cell dynamics of adipose tissue of MSG-treated (obese) and non-obese control mice. In autoradiographs of epon-embedded pieces we studied the cell kinetics of adipose tissue during the refeeding period after weight gains were demonstrated in MSG-treated and control mice. Autoradiographic studies have been thought inadequate to assess cell kinetics of adipose tissue (7). However, this technique has great advantage in which we can analyze the process of cell renewal while observing the morphology (8-12). Through our study we concluded that new fat cell formation occurred in both groups of mice during the refeeding period, and was more active in MSG-treated (obese) mice.

\section{MATERIALS AND METHODS}

A total of 72 mice (Jcl-ICR strain), approximately 4 months of age, were used in the present study. Thirty-six mice were rendered obese by a subcutaneous injection of $10 \% \mathrm{MSG}, 2 \mathrm{mg} / \mathrm{g}$ body weight, every $24 \mathrm{~h}$ for the first 5 postnatal days. Another group of 36 mice, which were injected with saline solution, $0.02 \mathrm{ml} / \mathrm{g}$ body weight, every $24 \mathrm{~h}$ for the first 5 postnatal days, served as the control. Each litter of mice (4 MSG-treated and 4 control mice) was nursed by one mother. They were fed CE-10 (CLEA Japan Inc.) mouse chow ad libitum and housed in a room on a 12-h light/dark cycle. At 4 months of age, 66 mice were deprived of all food and given only a glucose-electrolyte solution containing $12 \%$ glucose; $\mathrm{Na}, 35 \mathrm{mEq} /$ liter; $\mathrm{K}, 20 \mathrm{mEq} /$ liter; $\mathrm{Cl}, 35 \mathrm{mEq} /$ liter and lactate, $20 \mathrm{mEq} /$ liter for $20-40$ days.

Method of ${ }^{3} H$-thymidine administration. 1. Flash labeling experiment: On the 20-40th day of the induced deprivation, when the body weight of the non-obese control mice had dropped to about $65 \%$ of their weights before treatment and that of the MSG-treated obese mice was about 45\%, three control and three MSGtreated mice were each given a single injection of ${ }^{3} \mathrm{H}$-thymidine containing $5 \mu \mathrm{Ci}$ per gram body weight, and were sacrificed under ether anesthesia $30 \mathrm{~min}$ after injection. Another 60 mice were refed regular laboratory chow (CE-10) ad libitum after 20-40 days of induced deprivation. After 2, 4, 6, 8, 10, 13 and 35 days of refeeding, 3 each of the refed control and MSG-treated mice were given a single injection of ${ }^{3} \mathrm{H}$-thymidine containing $5 \mu \mathrm{Ci}$ per gram body weight and sacrificed 30 
min after injection. Three from each group were sacrificed in the same way as controls without deprivation.

2. Cumulative labeling experiment: Three each of the control and MSGtreated mice in each group received a series of 6,12 and 18 subcutaneous injections of ${ }^{3} \mathrm{H}$-thymidine ( $2 \mu \mathrm{Ci} / \mathrm{g}$ body weight each time) every $8 \mathrm{~h}$ for 2,4 and 6 days after refeeding. They were sacrificed at $30 \mathrm{~min}$ after the last injection with ether anesthesia.

Technique of autoradiography. The epididymal adipose tissue of all sacrificed animals was removed. The total tissue of each mouse was weighed and cut into regional segments (head, body and tail). The body was further cut into small pieces. Specimens were fixed for $1 \mathrm{~h}$ in $4 \%$ glutaraldehyde in cacodylate buffer adjusted to $\mathrm{pH}$ 7.4. They were then rinsed in several changes of cacodylate buffer over a period of $1 \mathrm{~h}$, and postfixed in $2 \%$ osmium tetroxide for $2 \mathrm{~h}$. The tissue was dehydrated in a graded ethanol series and embedded in epoxy resin. Semithin sections of one micron thickness were mounted on glass slides, dipped in KODAK NTB2 nuclear emulsion and developed in FD-111 after 4 weeks exposure. Sections were studied with toluidine blue stain.

Counting of labeled cells in the flash labeling experiment. On our autoradiographs, the mean grain count of the labeled cells was about 40 . In the flash labeling experiment, the total labeling index of the epididymal adipose tissue was scored as the percentage of labeled cells compared to the total number of cells counted, about 1,000 per mouse. At the same time, labeled cells were classified into 3 groups: adipocytes, endothelial cells and undifferentiated mesenchymal cells with no specific features (M). In the MSG-treated mice, the macrophage-like cells that were observed surrounding the necrotic fat cells were classified separately.

Measurement of adipocyte size. Photographs were taken of the specimens that were used in the flash labeling experiment and dimensions of about 200 cells which contain one fat droplet per mouse were measured by image analyzer (Manual Optical Picture Analyzing System MOP/AMO3, Kontron). Dimensions of fat cells were measured by tracing the outline of fat droplet on the picture with magnetic cursor.

Counting of labeled cells in the cumulative labeling experiment. In the cumulative labeling experiment, we scored the labeling index of four types of cell (fat cells $(F)$, endothelial cells $(E)$, undifferentiated mesenchymal cells $(M)$ and macrophage-like cells $(\mathrm{m})$ ) separately. The labeling index of each cell type was expressed as the percentage of each labeled cell type in a total count of 200 nucleated cells of each type per mouse. The labeling index on each day was expressed as the mean value of labeling index of three animals.

More precise examination under ultramicroscopy. In order to classify the labeled cells more precisely, ultramicroscopical study was performed. Ultrathin sections were made from some epon blocks obtained from mice in the cumulative labeling experiment. All sections were stained with lead citrate, and observed in a HITACHI HS50 electron microscope. Labeled and non-labeled cells were observed 
ultramicroscopically, comparing with matched autoradiographic semithin sections.

\section{RESULTS}

Body weight and Lee index

The mean body weight of the control mice, which was $40.7 \pm 2.3$ (mean \pm SD) $\mathrm{g}$ before deprivation, dropped to $26.3 \pm 3.4$ (mean $\pm \mathrm{SD}) \mathrm{g}$ at the end of food deprivation for 20-40 days (Fig. 1). Nasoanal length was 10.3 \pm 0.7 (mean \pm SD) $\mathrm{cm}$, which was constant before and after deprivation. Lee index was $333.4 \pm 18.4$ (mean $\pm \mathrm{SD}$ ) before deprivation and $285.9 \pm 12.5$ (mean $\pm \mathrm{SD}$ ) at maximum weight loss (Fig. 2). In our preliminary experiments, the control mice died within a few days after their weight dropped to below $65 \%$ of pre-deprivation body weight. Thus refeeding of the control group was instituted when their body weights dropped to $65 \%$ of pre-experimental weight. In contrast, the mean body weight of the MSG-treated (obese) mice was $49.0 \pm 6.3$ (mean \pm SD) $g$ before deprivation and nasoanal length was $9.7 \pm 0.2$ (mean $\pm \mathrm{SD}$ ) $\mathrm{cm}$. Lee index was $376.9 \pm 15.0$ (mean \pm SD). This data shows that the MSG-treated mice are smaller in stature, but fatter than the control. The rate of weight reduction of the MSG-treated mice was faster than in the control during food deprivation. The mean body weight dropped to $22.5 \pm 3.6$ (mean $\pm \mathrm{SD}$ ) g in 20-40 days (Fig. 1). Nasoanal length was constant before and after deprivation. When maximum weight loss was attained, the Lee

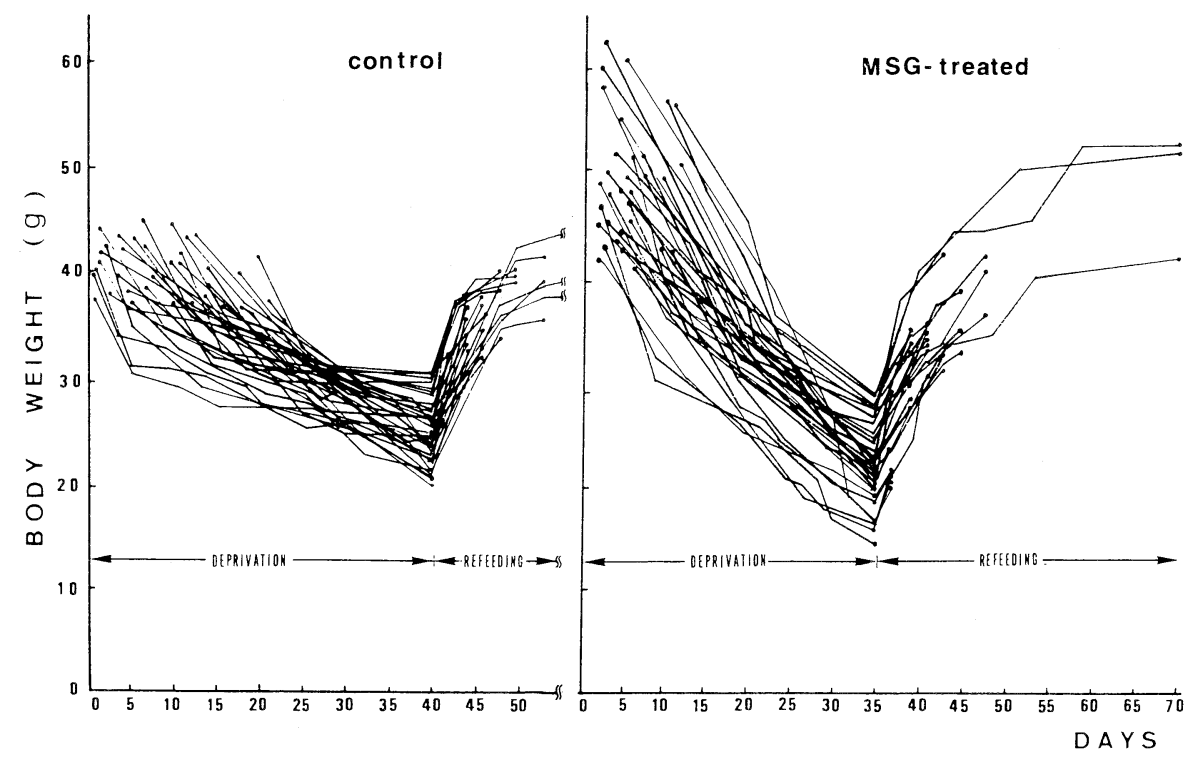

Fig. 1. Body weight curve of each mouse during deprivation and refeeding period. During the refeeding period, each mouse was injected with ${ }^{3} \mathrm{H}$-thymidine and sacrificed. 


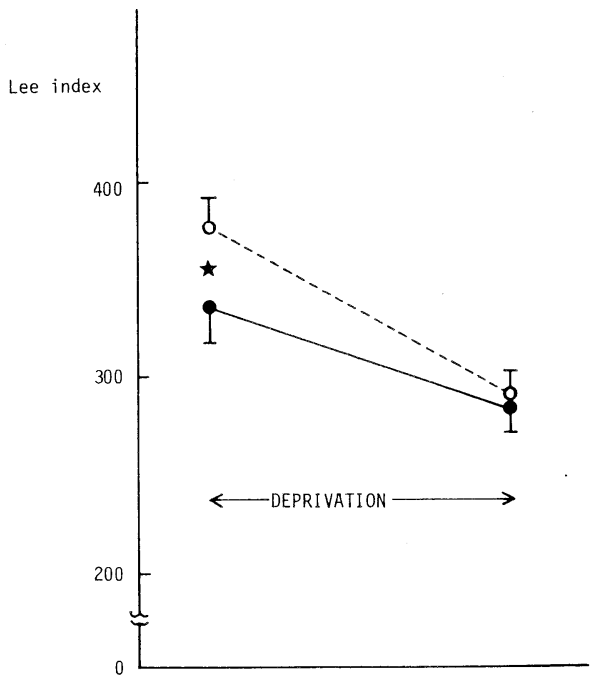

Fig. 2. Lee indices ( $\bullet$, control; $\bigcirc$, MSG-treated) before and after deprivation. Values are means $\pm S D$. When the Lee index $(=\sqrt[3]{\text { body weight }(\mathrm{g}) / \text { nasoanal }}$ $\overline{\text { length }(\mathrm{cm})} \times 1,000$ ) shows more than 340 , the mouse appears obese. Asterisk shows significantly different $(p<0.001)$ from corresponding control value by Student's $t$ test.

index was $290 \pm 14.3$ (mean \pm SD) (Fig. 2). Though the MSG-treated mice lost more body weight during deprivation, their Lee index was not less than the control mice, because their nasoanal length was shorter than that of the control mice (Fig. 2). The degree of emaciation closely resembled that of the control group. However, the MSG-treated mice were more active and vigorous than the normal mice during deprivation. In our preliminary experiments, the MSG-treated mice remained alive for about 1 week even when their body weight dropped to $45 \%$ of their pre-experimental body weight. We began to refeed when both mice showed similar measurement on the Lee index (285-290). Within 13-15 days after the onset of refeeding, body weights of the control mice had returned to their previous levels, and body weights of MSG-treated ones rapidly increased to about $80 \%$ of pre-deprivation level, returning to $100 \%$ after 35 days (Fig. 1).

\section{Epididymal adipose tissue weight}

In mice which had attained the maximum weight loss, all adipose tissue was markedly atrophied. Subcutaneous and mesenteric adipose tissue was hardly recognizable on gross examination. The amount of epididymal adipose tissue was small and the wet weight of the unilateral (left side) epididymal adipose tissue was $135.0 \pm 40.0$ (mean $\pm \mathrm{SE}$ ) $\mathrm{mg}$ for the control mice, and $200 \pm 31.0$ (mean $\pm \mathrm{SE}$ ) $\mathrm{mg}$ for the MSG-treated mice. Upon refeeding of a normal diet, the weight of the epididymal adipose tissue of both mice increased proportionately to body weight 


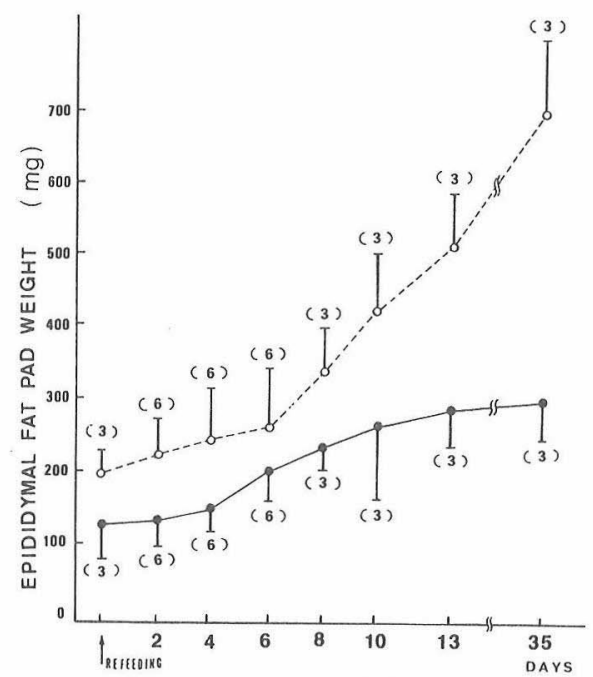

Fig. 3. Wet weight curve of the unilateral (left side) epididymal fat pad ( $\bullet$, control; $\bigcirc$, MSG-treated). ( ) shows the number of mice. Values are means \pm SE.

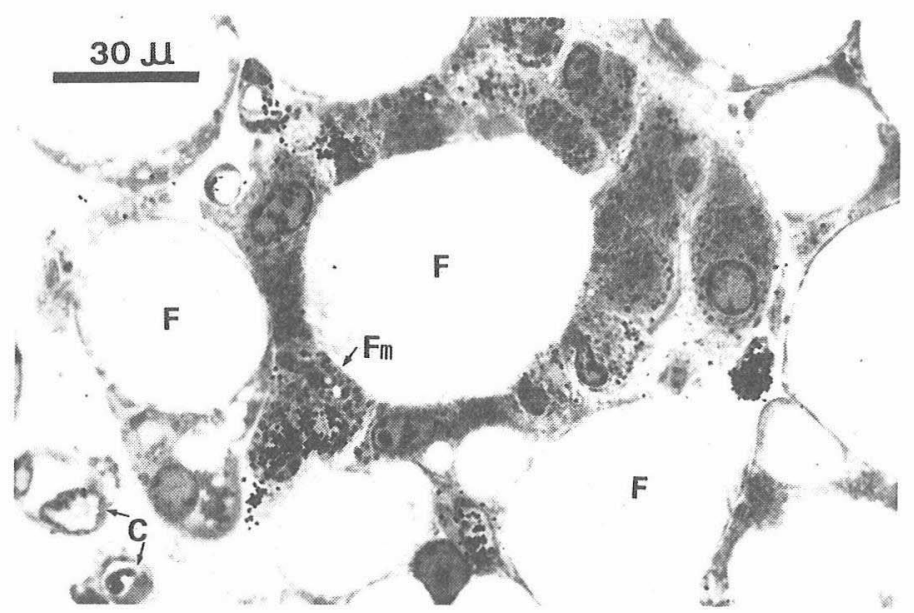

Fig. 4. ${ }^{3} \mathrm{H}$-thymidine autoradiograph of epon-embedded adipose tissue taken after 6 days of continuous labeling in MSG-treated mice. Labeled macrophage-like cells surrounding a necrotic fat cell. F, adipocyte; Fm, macrophage-like cell around fat; C, capillary lumen.

gain, and finally returned to pre-experimental levels (Fig. 3).

Morphology of the adipose tissue and cell

In all mice that had attained the maximum weight loss, adipocytes were found to be reduced in size and to have some small lipid droplets in the cytoplasm under 
microscopic observation (12). In the MSG-treated mice, several various-sized fat cells were seen, but some adipocytes had lost their cell membranes and were surrounded by macrophage-like infiltrating cells. This finding shows fat cell necrosis (Fig. 4). During refeeding, adipocyte size increased relative to increases in both body weight and epididymal fat pad weight in both mice (Fig. 5).

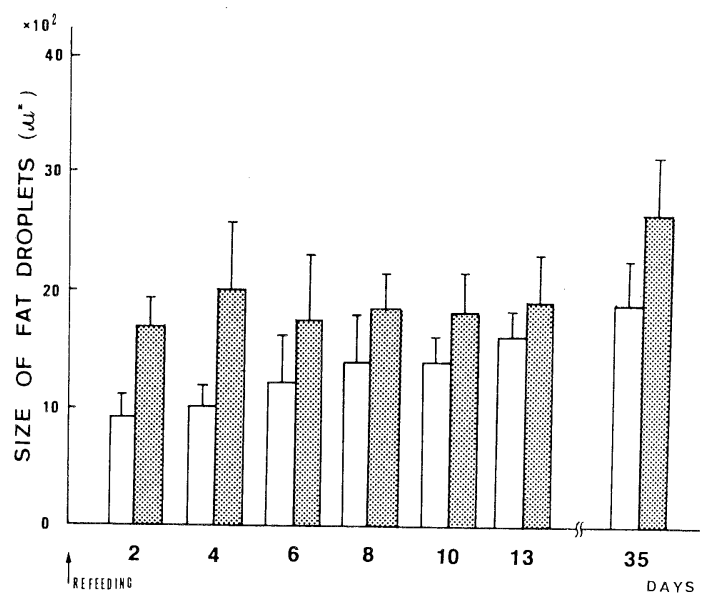

Fig. 5. Means of adipocyte size from three mice during refeeding period (open column, control; closed column, MSG-treated). Dimensions of about 200 cells which contain one large fat droplet per mouse were measured by image analyzer. Values are means $\pm S E$.

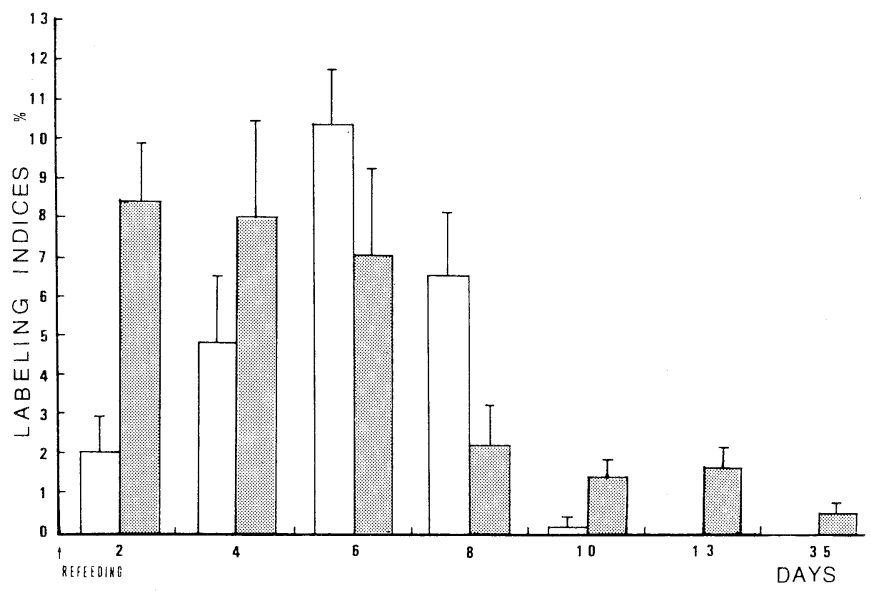

Fig. 6. Labeling indices of the epididymal adipose tissue from three mice at each day in flash labeling experiment (open column, control; closed column, MSGtreated). Values are means $\pm \mathrm{SE}$. 

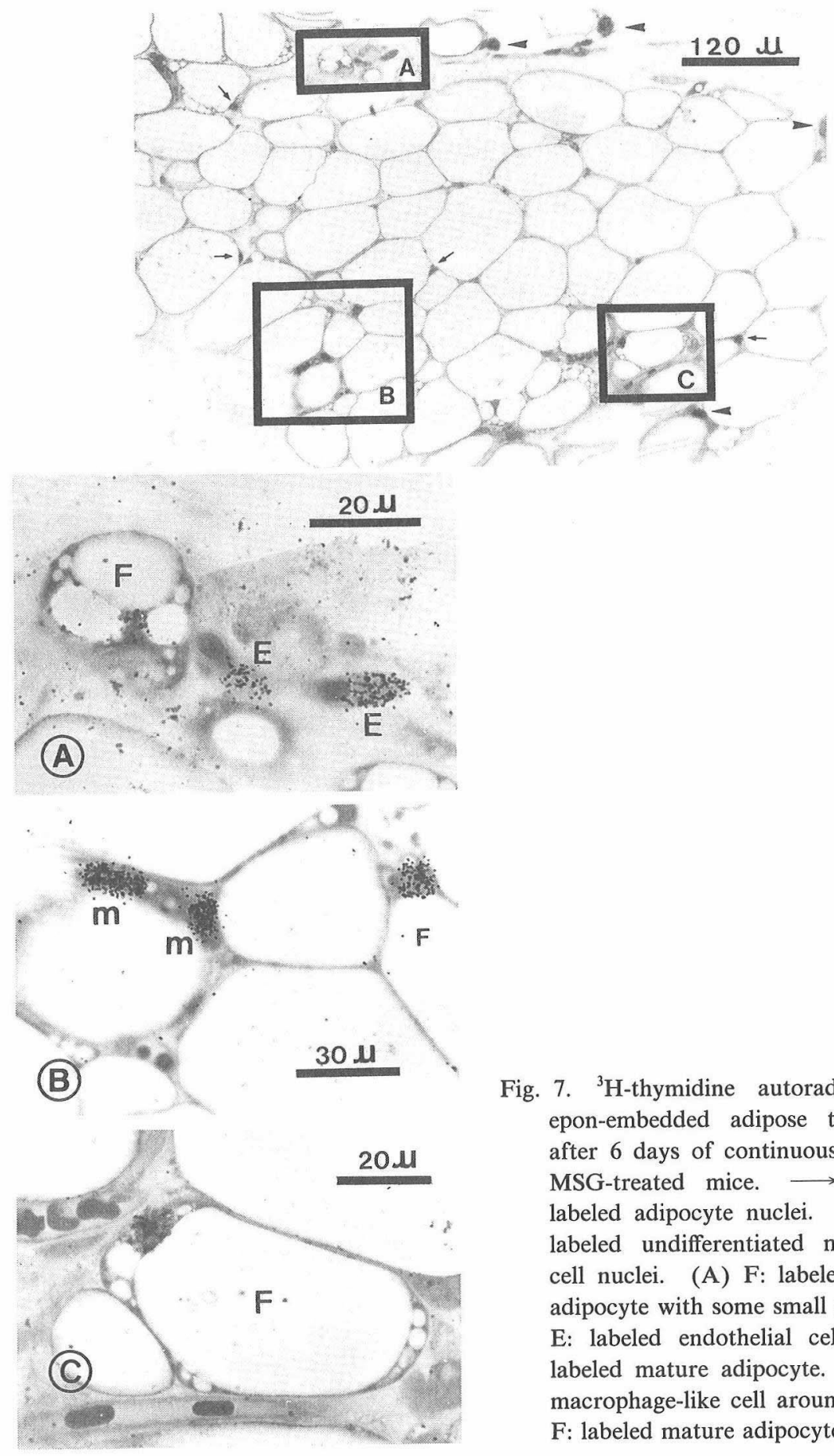

Fig. 7. ${ }^{3} \mathrm{H}$-thymidine autoradiograph of epon-embedded adipose tissue taken after 6 days of continuous labeling in MSG-treated mice. $\longrightarrow$ shows the labeled adipocyte nuclei. shows labeled undifferentiated mesenchymal cell nuclei. (A) F: labeled immature adipocyte with some small fat droplets. E: labeled endothelial cells. (B) F: labeled mature adipocyte. m: labeled macrophage-like cell around fat. (C): F: labeled mature adipocyte. 


\section{Flash labeling autoradiography}

In the flash labeling experiment, cell proliferation was seen on day 2 of refeeding in both groups of mice (Fig. 6). No labeled cells could be seen before refeeding.

In the control mice, cell proliferation was most active on day 6 , with the mean labeling indices of the epididymal adipose tissue in total the highest, an average $10.4 \pm 1.4 \%$ (mean $\pm \mathrm{SE}$ ) at this point, decreasing thereafter until day 13 of refeeding, when no labeled cells were seen (Fig. 6). On the other hand, in the MSG-treated mice, cell proliferation was the most active on day 2 of refeeding. At this point, the mean labeling index of the epididymal adipose tissue in total was $8.4 \pm 1.5 \%$ (mean $\pm \mathrm{SE}$ ), and thereafter gradually decreased (Fig. 6). In the MSG-treated mice, a few cells were found to be labeled on days 13 and 35. In the

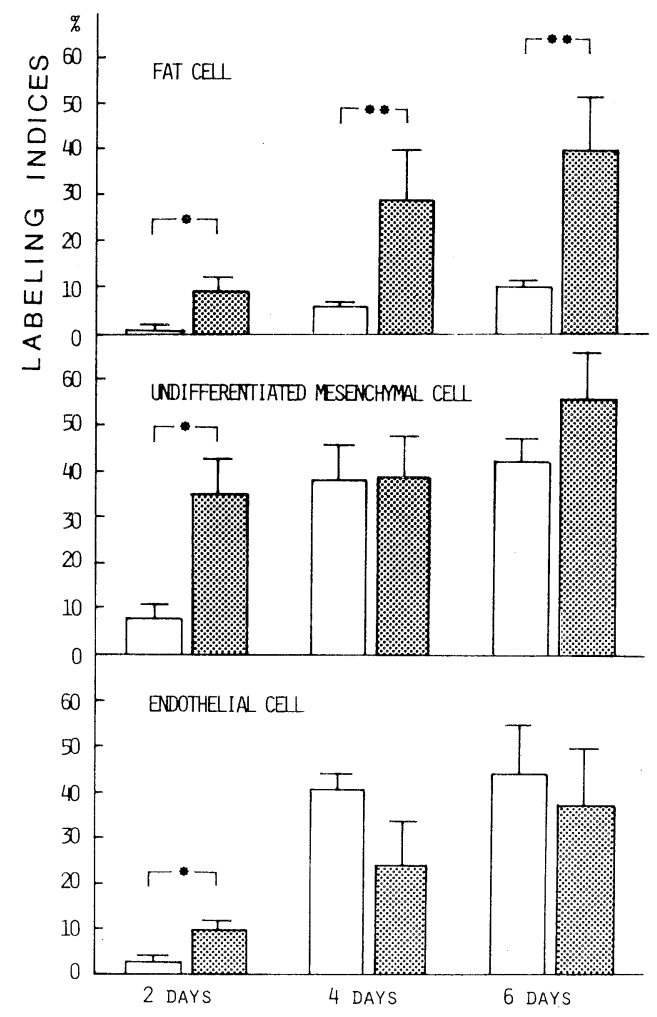

Fig. 8. The mean labeling indices of each cell type from three mice at each day after refeeding in the cumulative labeling experiment. Labeling index of each cell type is the percentage of each labeled cell type in a total count of 200 nucleated cells of each type per mouse (open column, control; closed column, MSG-treated). Values are means \pm SE. Asterisks show significantly different from corresponding control value by Student's $t$ test $\left({ }^{*} p<0.025,{ }^{*} p<0.05\right)$. 
flash labeling experiment, endothelial cells and undifferentiated mesenchymal cells accounted for most of the labeled cells in both groups of mice, and in addition to both cells, many macrophage-like cells were labeled in the MSG-treated mice. Immature adipocytes with small fat droplets were rarely labeled, but mature adipocytes with large fat droplet were not labeled. The control and MSG-treated mice that had not been subjected to deprivation had few labeled cells.

\section{Cumulative labeling autoradiography}

Figure 7 shows the ${ }^{3} \mathrm{H}$-thymidine autoradiograph taken after 6 days of continuous labeling. About half of the observed adipocyte nuclei were labeled. Figure 8 shows labeling indices of each cell type on each day of refeeding. Labeled cells, which had replicated during ${ }^{3} \mathrm{H}$-thymidine injection, increased gradually in both groups of mice. Labeling indices of all types of cell were higher in the MSG-treated mice than in the control mice on day 2 of refeeding. The labeling indices of adipocytes gradually increased with weight gain in both mice, and were higher in the MSG-treated mice than in the control mice significantly. However, no significant difference in labeling indices of the other cell type was found between the MSG-treated and control mice on days 4 and 6 of refeeding. The labeling indices of the macrophage-like cells, which surrounded fat droplets in the MSG-treated mice, were high $(34.2 \pm 10.3,40.3 \pm 15.2$ and $63.5 \pm 18.1$ on days 2,4 and 6 of refeeding). These proliferated macrophage-like cells, which seemed to contribute to cleaning the destructed fat cells, were not seen in the control mice.

\section{Macroscopic changes in other organs}

Before deprivation, the heart, lungs and kidneys of the MSG-treated mice were smaller than those of the control mice. These organs remained identical in size before and after deprivation in both groups of mice. The liver in the MSG-treated mice, however, which had been very fatty and larger than that of the control mice before deprivation, decreased in size and amount of fat during deprivation. In the control mice, liver size did not change.

\section{DISCUSSION}

Neonatal mice were rendered obese by subcutaneous injections of MSG for the first five postnatal days. This treatment causes an injury to both the nucleus arcuatus, n.ventromedialis and some nuclei of the hypothalamus in mice (13). At the onset of puberty, MSG-treated mice gained weight excessively in comparison to the control (10).

In the present study, we examined how obese mice with hypothalamic lesions regulate body weight and adiposity when refed after the most severe and prolonged weight loss due to food deprivation. The MSG-treated mice lost about 55\% of their body weight within a period of 20-40 days, when given only a glucose-electrolyte diet devised by Kasubuchi et al. (14). On the other hand, the non-obese control 
mice lost about 35\% of their body weight under the same conditions. The difference of weight loss was due to the difference of adiposity between obese and non-obese mice. The mean Lee index, which shows adiposity of mice, was $376.9 \pm$ 15.0 (mean $\pm S D$ ) in the MSG-treated obese mice and $333.4 \pm 18.4$ (mean $\pm S D$ ) in the non-obese control mice before deprivation. The MSG-treated mice were significantly fatter than the control mice, but smaller than the non-obese control in nasoanal length. When maximum weight loss was attained, the mean Lee index, which was $290 \pm 14.3$ in the MSG-treated mice and $285.9 \pm 12.5$ in the control mice, showed no significant difference between both mice. Therefore, adipose mass was hypothesized to approach an ultimately low level, and both groups of emaciated mice were reaching optimally lean body mass.

When mice had attained the maximum weight loss, all adipose tissues were markedly atrophied. The weight of the unilateral epididymal adipose tissue decreased by $1 / 2$ of pre-deprivation level in the control and $1 / 3$ in the MSG-treated group. Upon refeeding with a normal diet, the weight of the epididymal adipose tissue of both mice increased proportionately to body weight gain and finally returned to pre-experimental levels. Other organs, with the exception of the liver in the MSG-treated mice, changed neither in size nor macroscopic appearance. Although the livers of the MSG-treated mice were fatty (15) and decreased slightly in size with loss of fat during deprivation, these changes in the liver did not significantly influence the decrease in total body weight during deprivation. From this study we deduced that the body weight of mice is regulated by the loss or deposition of fat in the adipose tissue.

Our main interest concerns how adiposity is controlled in mice. There are some controversies as to whether adipocyte replication occurs during refeeding following food deprivation $(12,14,16-18)$. Many investigations have shown that weight loss and gain result only from a decrease and subsequent increase in fat cell size with quantity of cells remaining unchanged $(16,17)$. In previous studies, the maximal weight loss that could be achieved was limited by the inability of the animals to survive for prolonged periods of total food deprivation. These studies failed to reveal the cell death and cell renewal in fatty tissue. We, however, used a model of severe starvation, in which mice seemed to approach the near level of lean body mass.

During deprivation, adipocytes were found to be reduced in size and some nuclei were pyknotic (12). In the MSG-treated mice, some various-sized fat cells remained, but they had lost cell membranes and were surrounded by macrophagelike infiltrating cells, which shows the occurrence of fat cell necrosis. In our previous study, we revealed that adipocyte in obese mice (over 24 weeks of age) is fragile with large fat droplet, resulting in adipocyte necrosis, and that the connective tissue elements increased (9). In our current study, we can see similar histology in emaciated MSG-treated mice before 20 weeks of age. The reason for this finding is unknown, but it is certain that adipocyte was destroyed more actively in the starved MSG-treated mice. 
During refeeding, fat is rapidly deposited in adipose tissue. Adipocyte size increased until pre-deprivation size. Concurrently, cell proliferation was observed to occur in the adipose tissue. This experiment indicates that the dynamics of cell proliferation differ between the MSG-treated and control mice. In the control mice, the proliferative activity peaked on day 6 of refeeding according to the results of the flash labeling experiment. In contrast, in the MSG-treated mice, the peak was attained on day 2 of refeeding and decreased gradually. In the results of the cumulative labeling experiment, the labeling indices of adipocyte in the MSGtreated mice were significantly higher than those in the control mice. We confirmed microscopically that labeled adipocytes were derived from the proliferated mesenchymal cells with accumulating fat. We cannot clearly explain why there is a difference in proliferative activity between the two groups of mice. We suppose, however, that the MSG-treated mice are more active and vigorous than the control mice after maximum weight loss is attained during deprivation, and that cell proliferative activity resumes soom after refeeding commences. In comparison to the control group, MSG-treated mice seem to have an ability to stimulate cell proliferation in the adipose tissue more rapidly, appear to have more mesenchymal cells which have the ability to differentiate into adipocytes, and adipocyte destruction was more aggressive. Even during the refeeding period, macrophage-like cells, which were highly labeled by ${ }^{3} \mathrm{H}$-thymidine, infiltrated around the necrotic fat cells. This indicates that the dynamics of cell renewal and destruction in the MSG-treated mice is more active than the control mice.

There are only two studies in addition to ours using ${ }^{3} \mathrm{H}$-thymidine autoradiography to examine whether or not adipocyte renewal occurs in non-obese rodents during refeeding after food deprivation $(14,17)$. Kasubuchi et al. showed that about $80 \%$ of adipose cells regenerate in mice (14). However, they failed to differentiate between adipose cells and other types of mesenchymal cells accurately, because of their use of paraffin-embedded $10 \mu \mathrm{m}$ sections. On the other hand, Miller et al. used epon-embedded $1 \mu \mathrm{m}$ sections in rats and identified all regenerated cells as being stromal (17). In their study, however, ${ }^{3} \mathrm{H}$-thymidine was injected only 4 times (an insufficient number to accurately label all adipocytes created during refeeding). Our present research points towards deficiencies and inconclusive results in the two previous studies and our current findings make up for those deficiencies. The precise differences between these two studies and ours were discussed fully in our previous paper (12). In any event, our current study revealed that the MSG-treated obese mice with hypothalamic lesions can regulate their body weight by both fat cell production and fat accumulation during the refeeding period after prolonged deprivation and fat cell dynamics is more active in the MSG-treated obese mice.

\section{REFERENCES}

1) Björntorp, P., and Yang, M. (1982): Refeeding after fasting in the rat: Effects on body 
composition and food efficiency. Am. J. Clin. Nutr., 36, 444-449.

2) Da Costa, E., and Clayton, R. (1950): Studies of dietary restriction and rehabilitation. I. Weight changes and food consumption. J. Nutr., 40, 537-549.

3) Levitsky, D. A., Faust, I., and Glassman, M. (1976): The ingestion of food and the recovery of body weight following fasting in the naive rat. Physiol. \& Behav., 17, 575580 .

4) Keesey, R. E. (1989): Physiological regulation of body weight and the issue of obesity. Med. Clin. N. Am., 73, 15-27.

5) Keesey, R. E. (1988): The body weight set point: What can you tell your patients? Postgrad. Med., 83, 114-127.

6) Lepkovsky, S. (1973): Hypothalamic-adipose tissue interrelationships. Fed. Proc., 32, 1705-1708.

7) Gurr, M. I., and Kirtland, J. (1978): Adipose tissue cellularity: A review. 1. Techniques for studying cellularity. Int. J. Obesity, 2, 401-427.

8) Desnoyers, F., and Durand, G. (1978): Proliferation of adipose cells and their lipid accumulation in the rat at the perinatal stage: Histoautoradiographic study. CR. Acad. Sci. Paris (D), 287, 357-359.

9) Ochi, M., Sawada, T., Kusunoki, T., and Hattori, T. (1988): Morphology and cell dynamics of adipose tissue in hypothalamic obese mice. Am. J. Physiol., 254, R740R745.

10) Ochi, M., Fukuhara, K., Sawada, T., Kusunoki, T., and Hattori, T. (1988): Development of the epididymal adipose tissue in monosodium glutamate-induced obese mice. J. Nutr. Sci. Vitaminol., 34, 317-326.

11) Ochi, M., Sawada, T., and Hattori, T. (1987): Tritiated thymidine autoradiographic study on postnatal development of epididymal adipose tissue in the normal mouse. Anat. Embryol., 177, 139-145.

12) Ochi, M., Yoshioka, H., Sawada, T., Kusunoki, T., and Hattori, T. (1991): New adipocyte formation in the mouse during refeeding after long-term deprivation. Am. J. Physiol., 260, R468-R474.

13) Tanaka, K., Shimada, M., Nakao, K., and Kusunoki, T. (1978): Hypothalamic lesion induced by injection of monosodium glutamate in suckling period and subsequent development of obesity. Exp. Neurol., 62, 191-199.

14) Kasubuchi, Y., Mino, M., Yoshioka, H., and Kusunoki, T. (1979): An autoradiographic study of new fat cell formation in adipose tissue in adult mice during malnutrition and refeeding. J. Nutr. Sci. Vitaminol., 25, 419-426.

15) Hamaoka, K., and Kusunoki, T. (1986): Morphological and cell proliferative study on the growth of visceral organs in monosodium 1-glutamate-treated obese mice. J. Nutr. Sci. Vitaminol., 32, 395-411.

16) Hirsch, J., and Han, P. W. (1969): Cellularity of rat adipose tissue: Effects of growth, starvation, and obesity. J. Lipid Res., 10, 77-82.

17) Miller, W. H., Jr., Faust, I. M., Goldberger, A. C., and Hirsch, J. (1983): Effects of severe long-term food deprivation and refeeding on adipose tissue cells in the rats. Am. J. Physiol., 245, E74-E80.

18) Smith, J. E., and DiGirolamo, M. (1974): Effect of weight reduction in the rat on epididymal fat-cell size and relative dispersion. Am. J. Physiol., 227, 420-424. 